

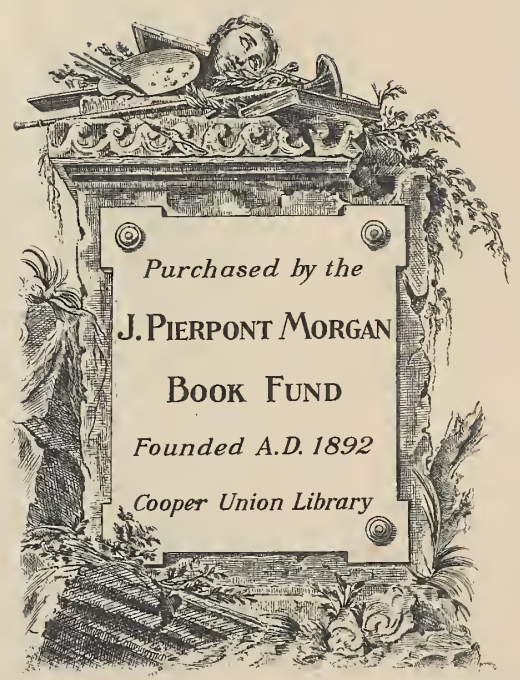




\section{ROBES ET FEMMES}

By Enrico Sacchetti

Paris: Dorbon-Ainé, 1913

f GT 510 .S15 1913 
- 


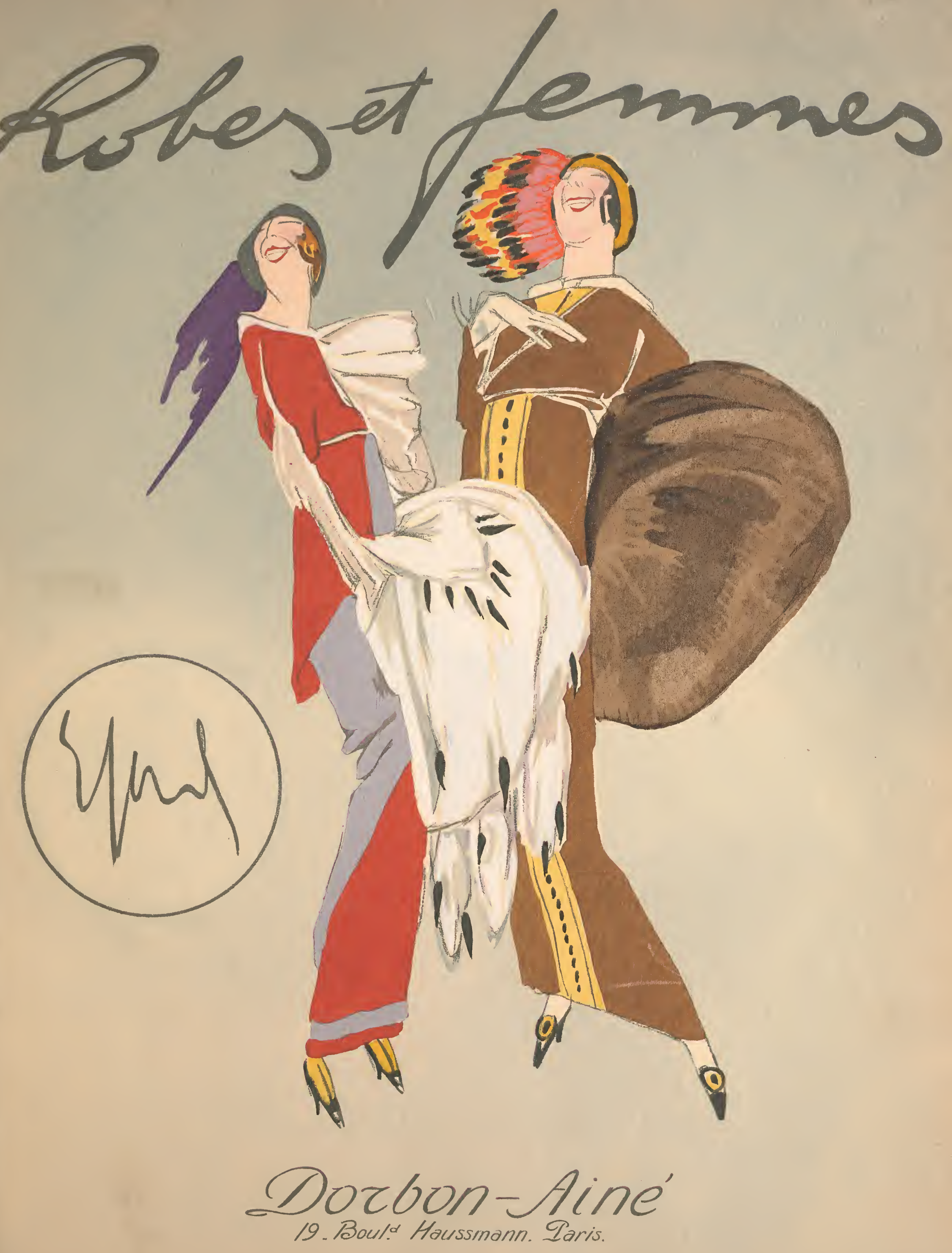






$$
\begin{aligned}
& M \\
& 391 \\
& \text { S119R } \\
& \text { Rare Book }
\end{aligned}
$$




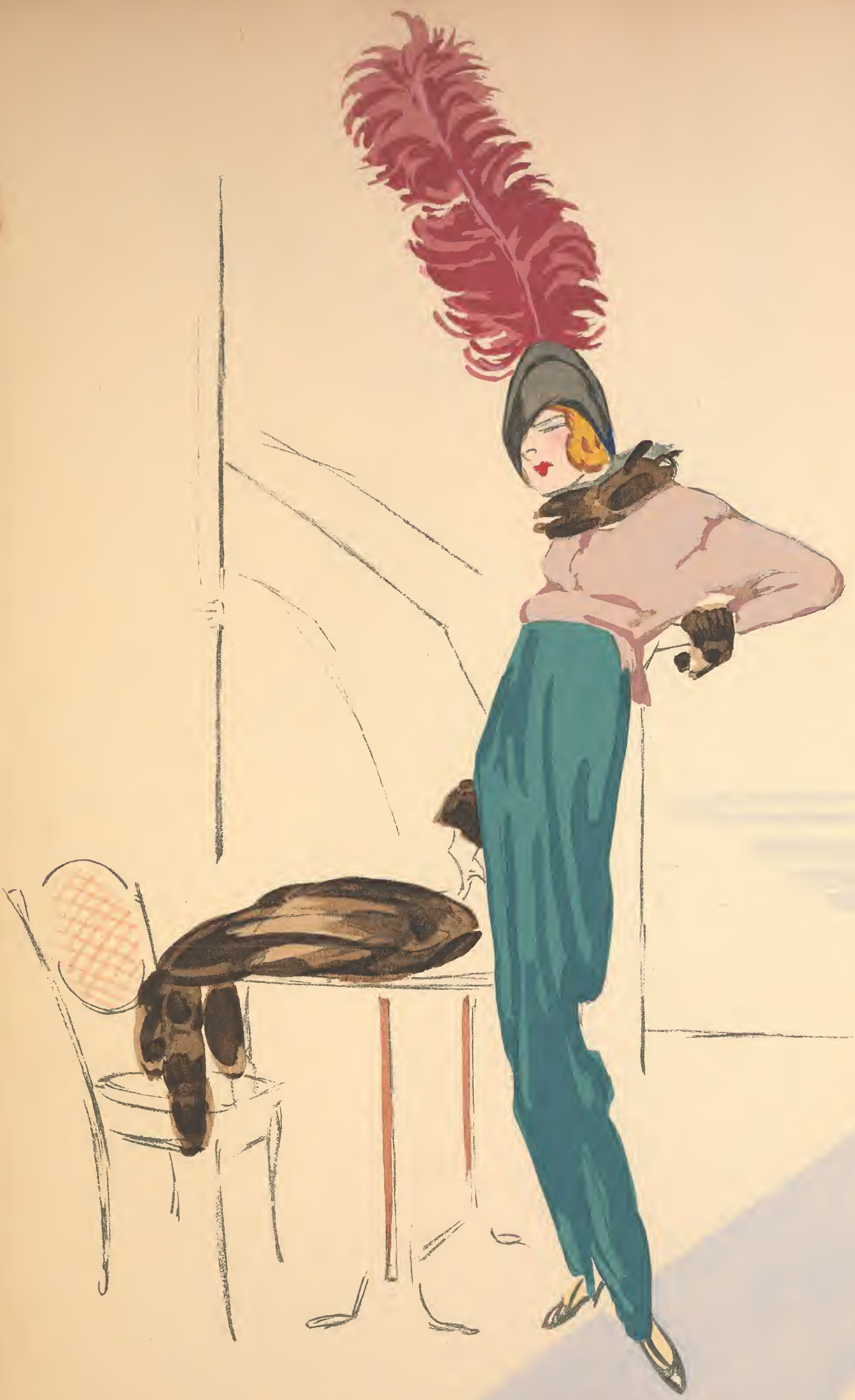





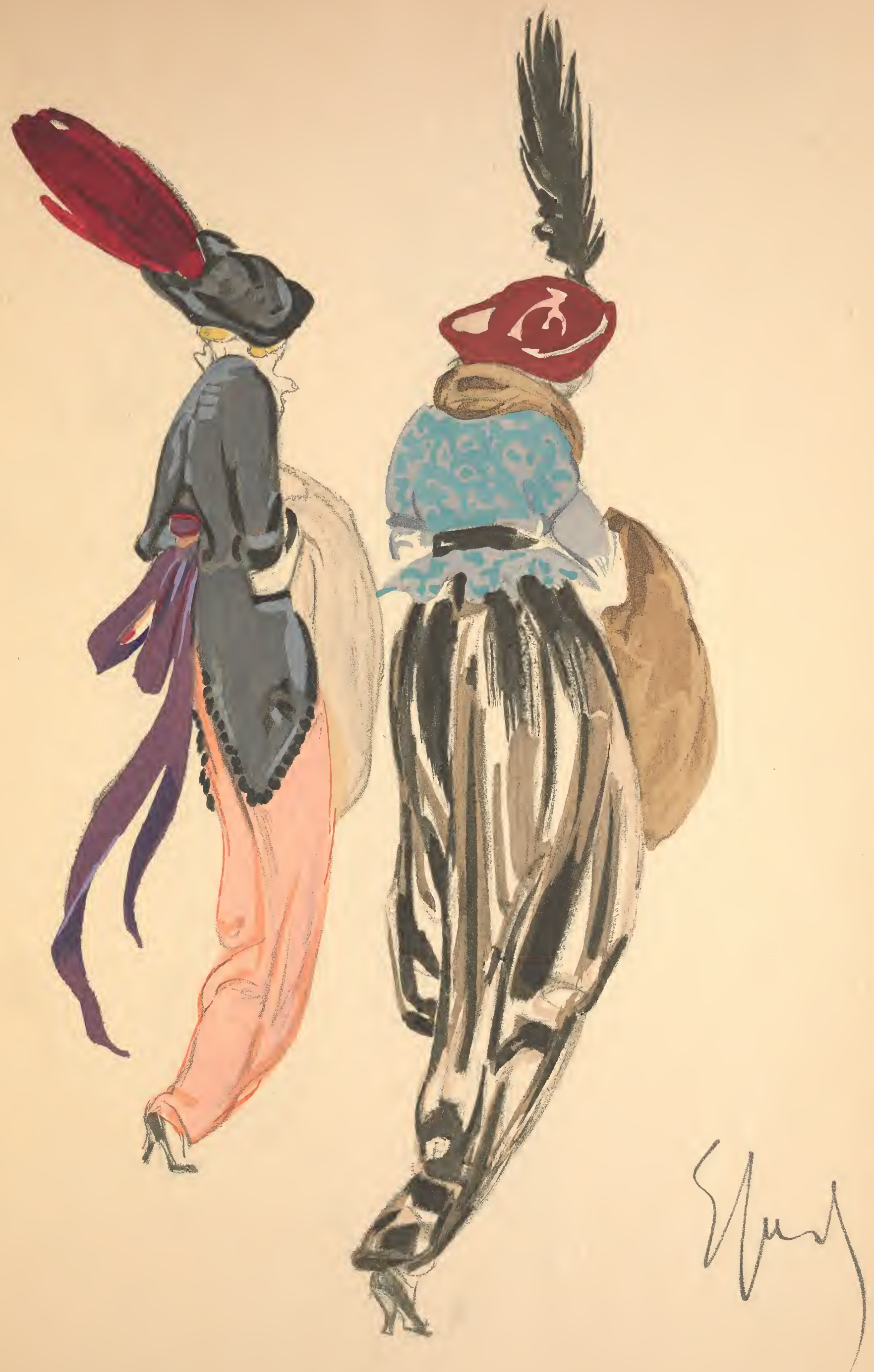




\section{1}




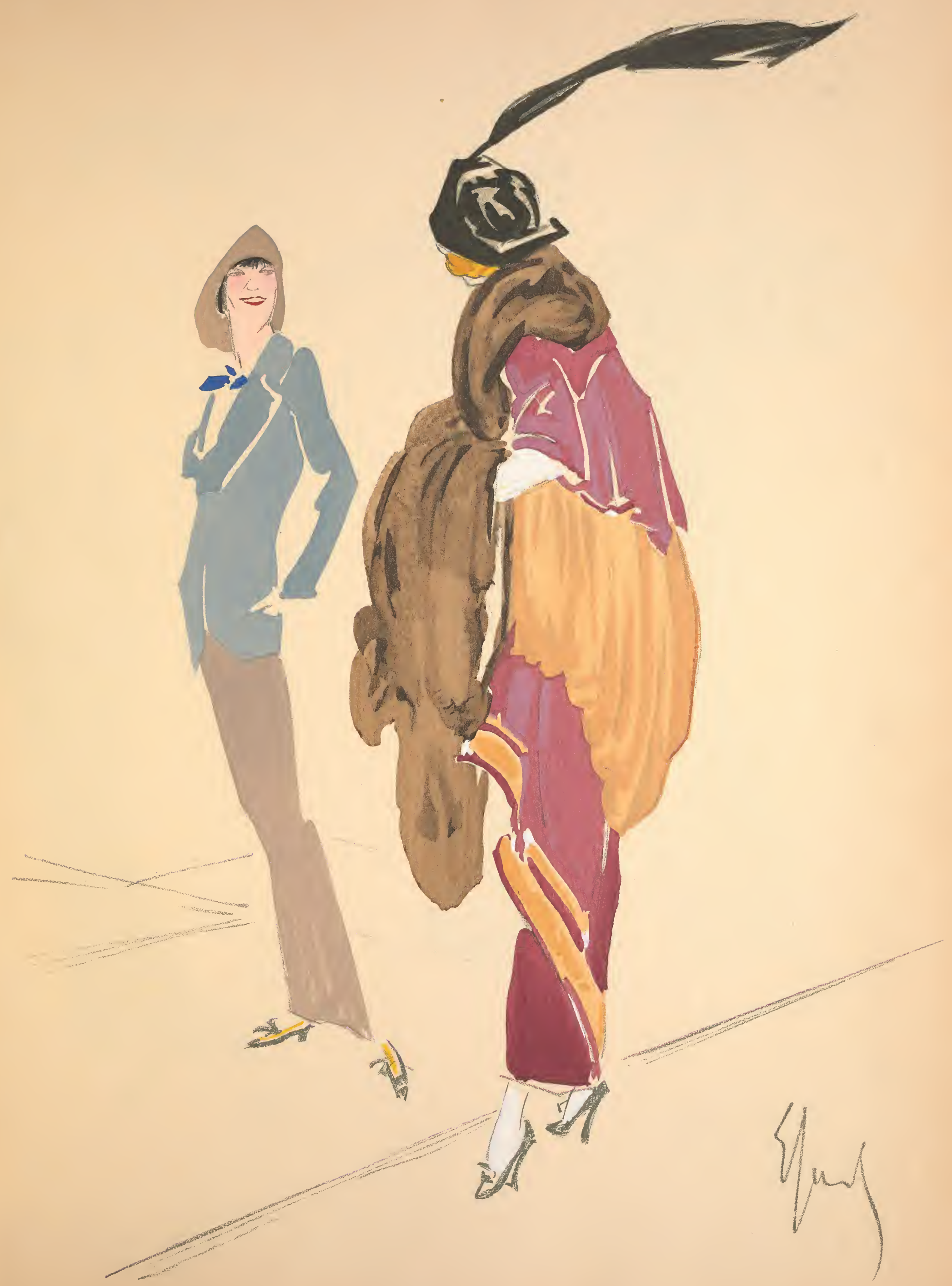




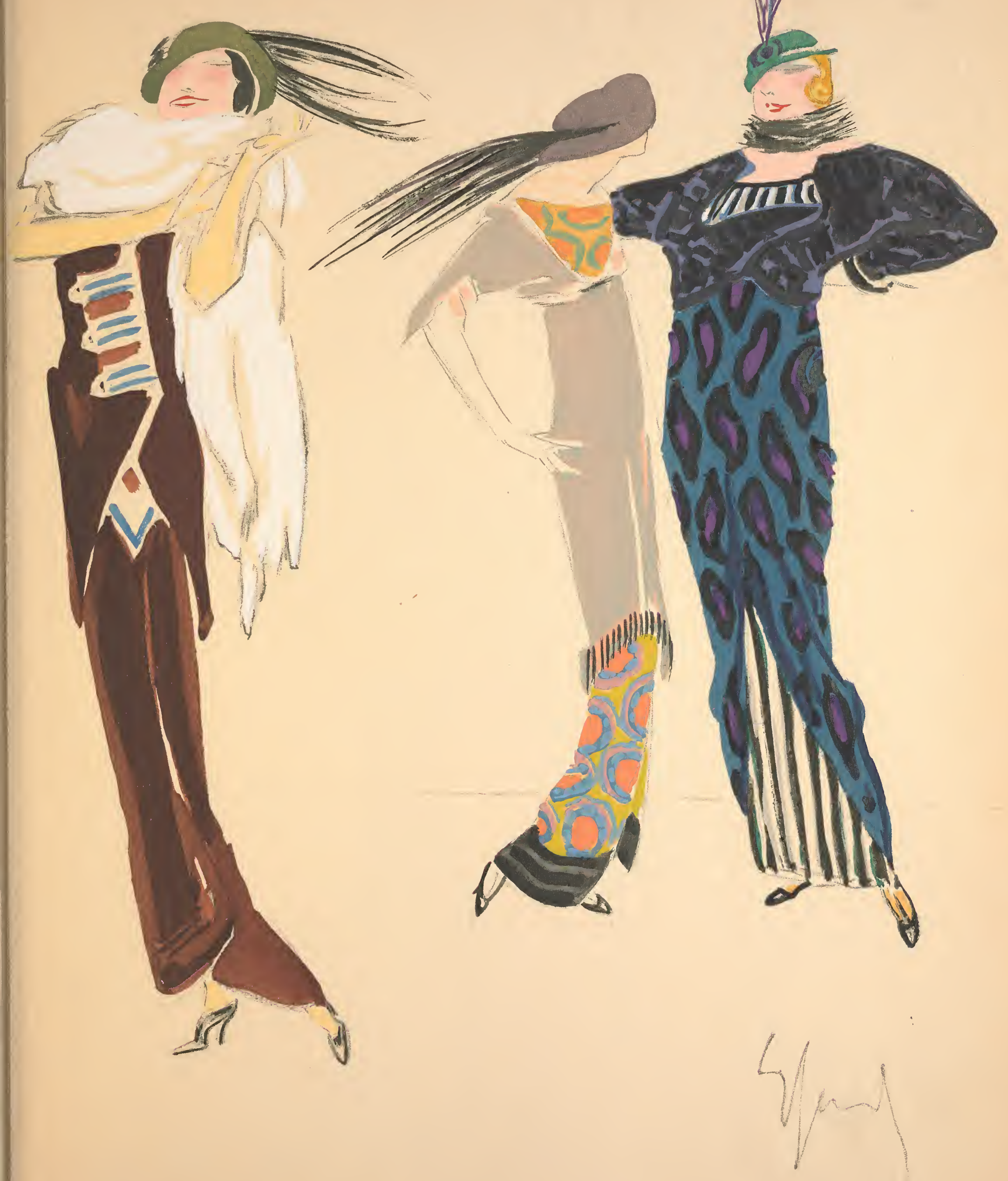




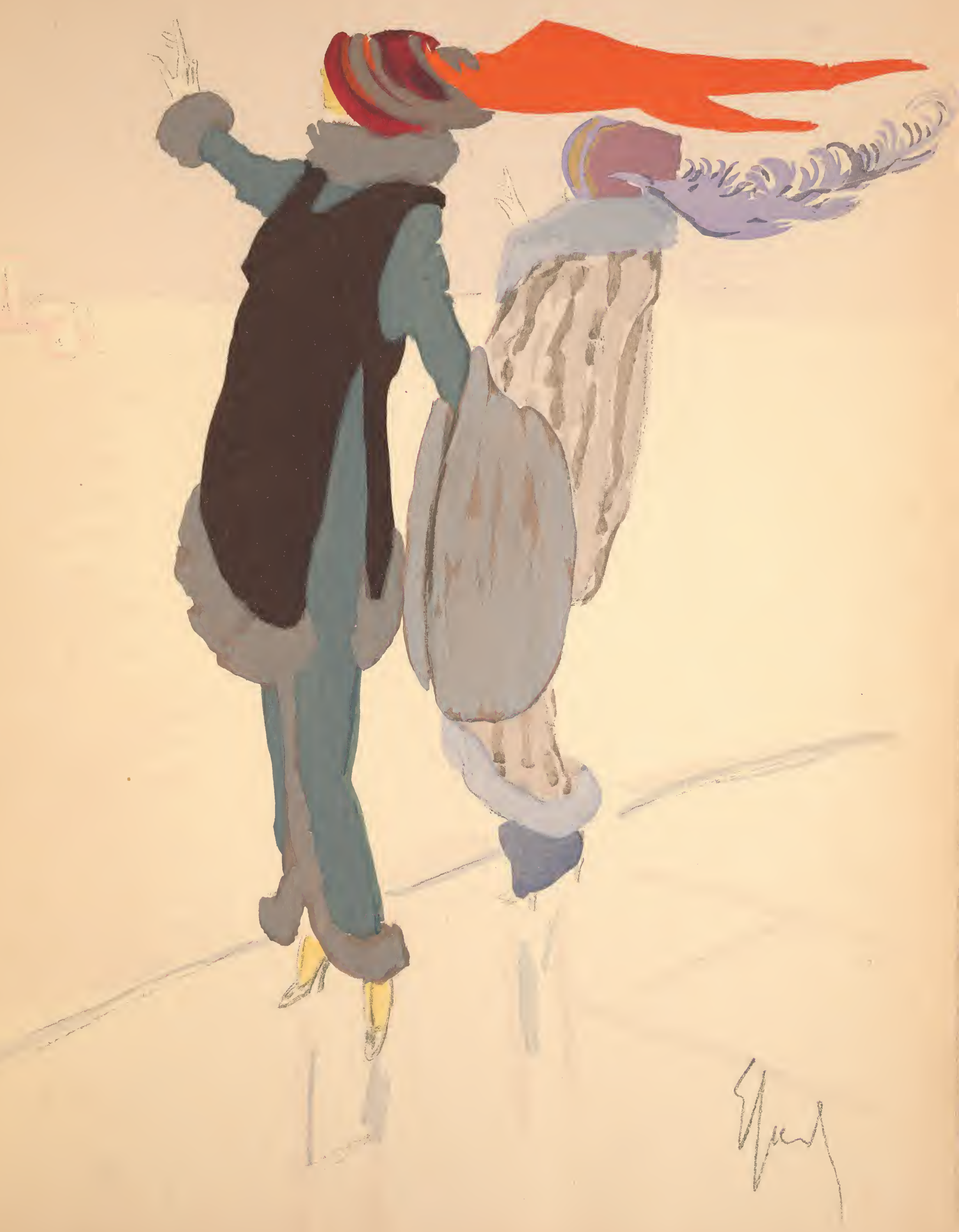


: 


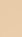




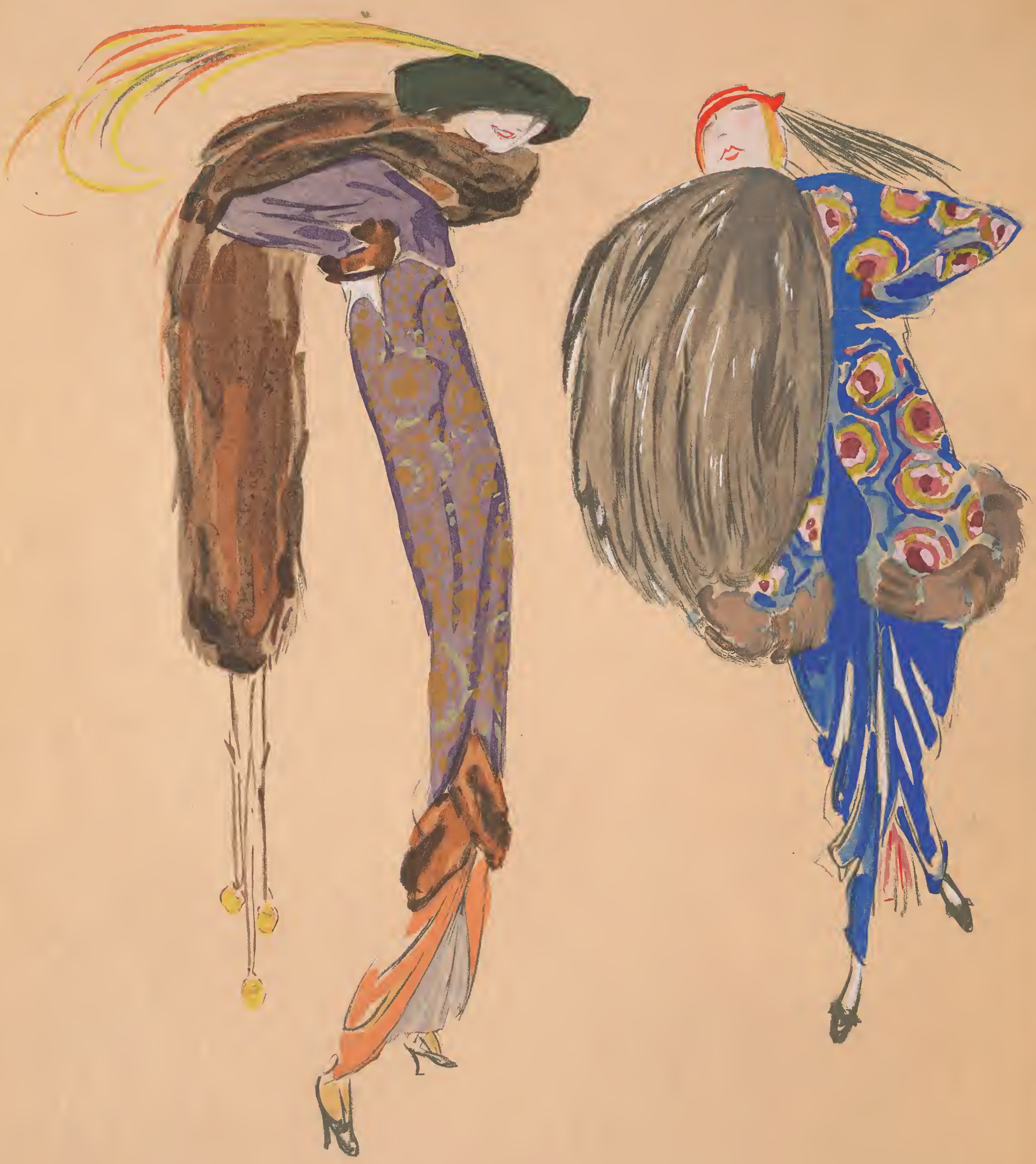





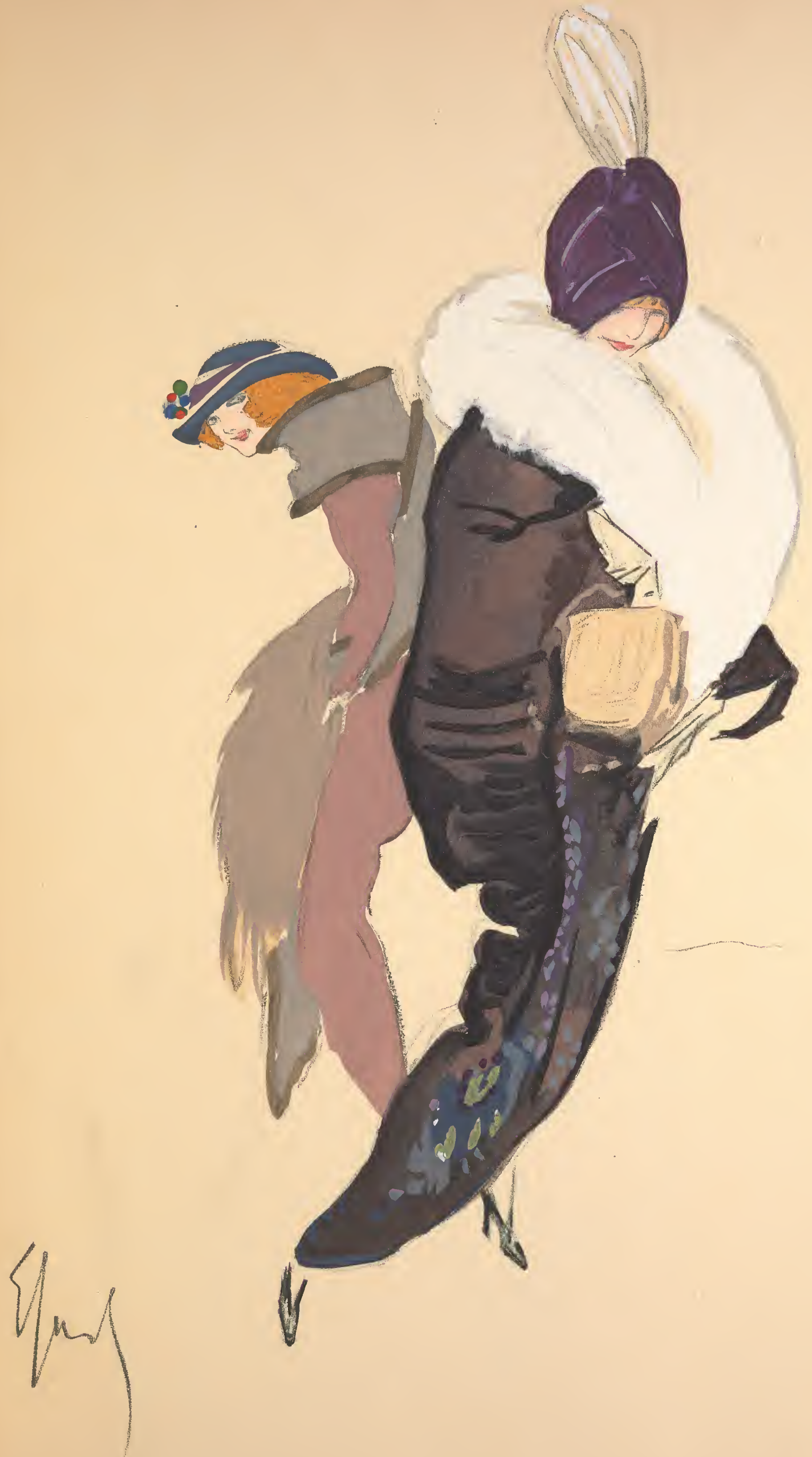





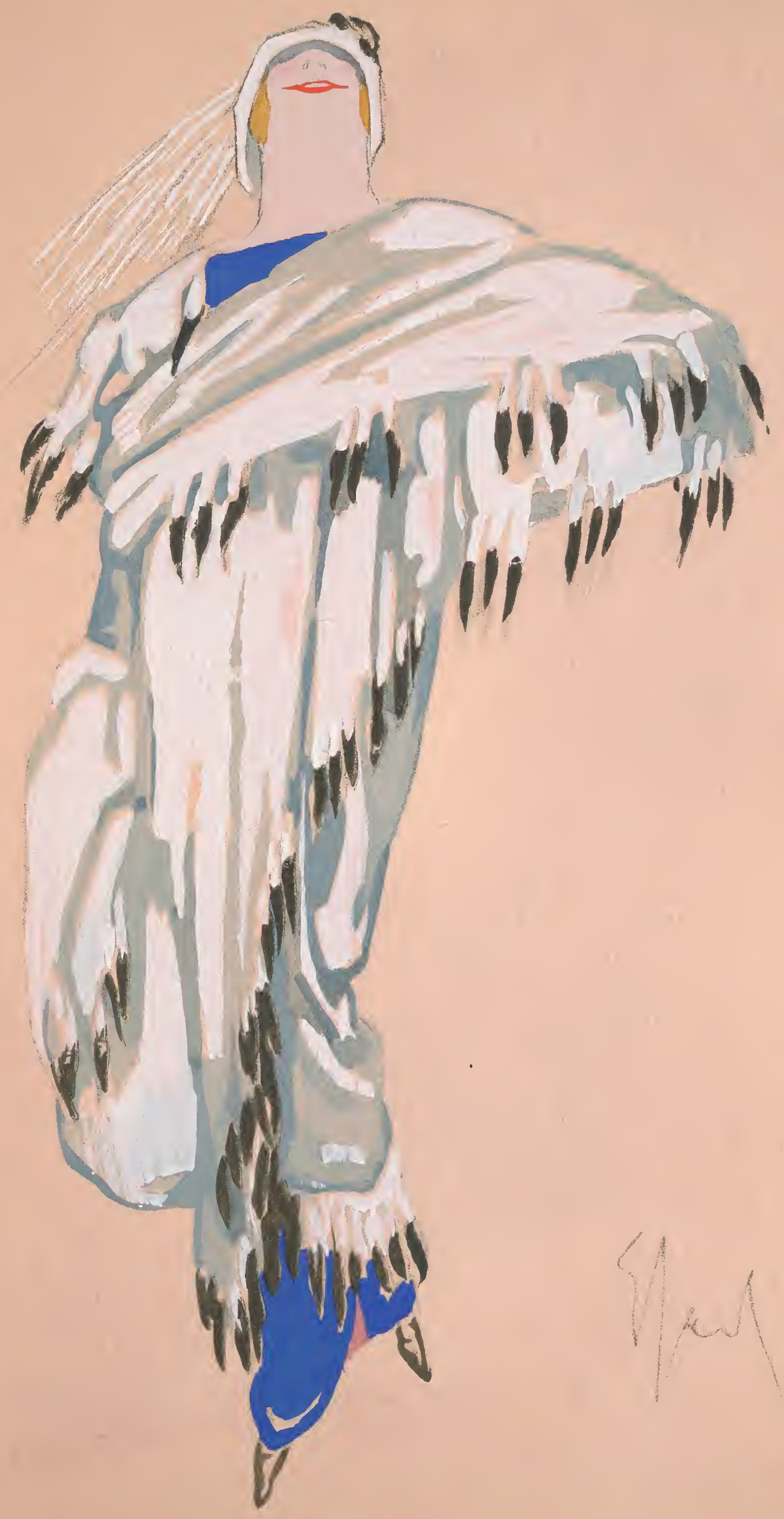





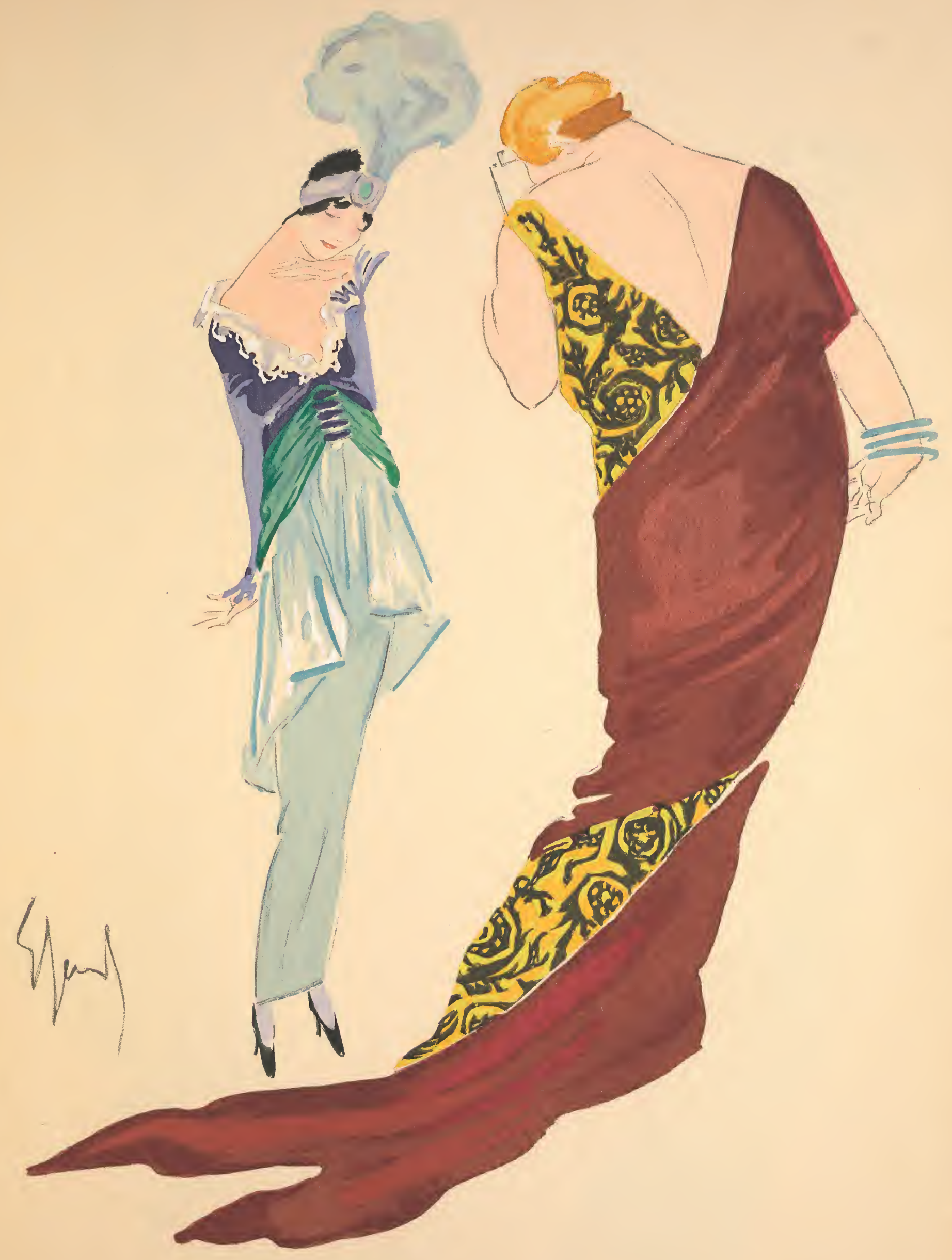





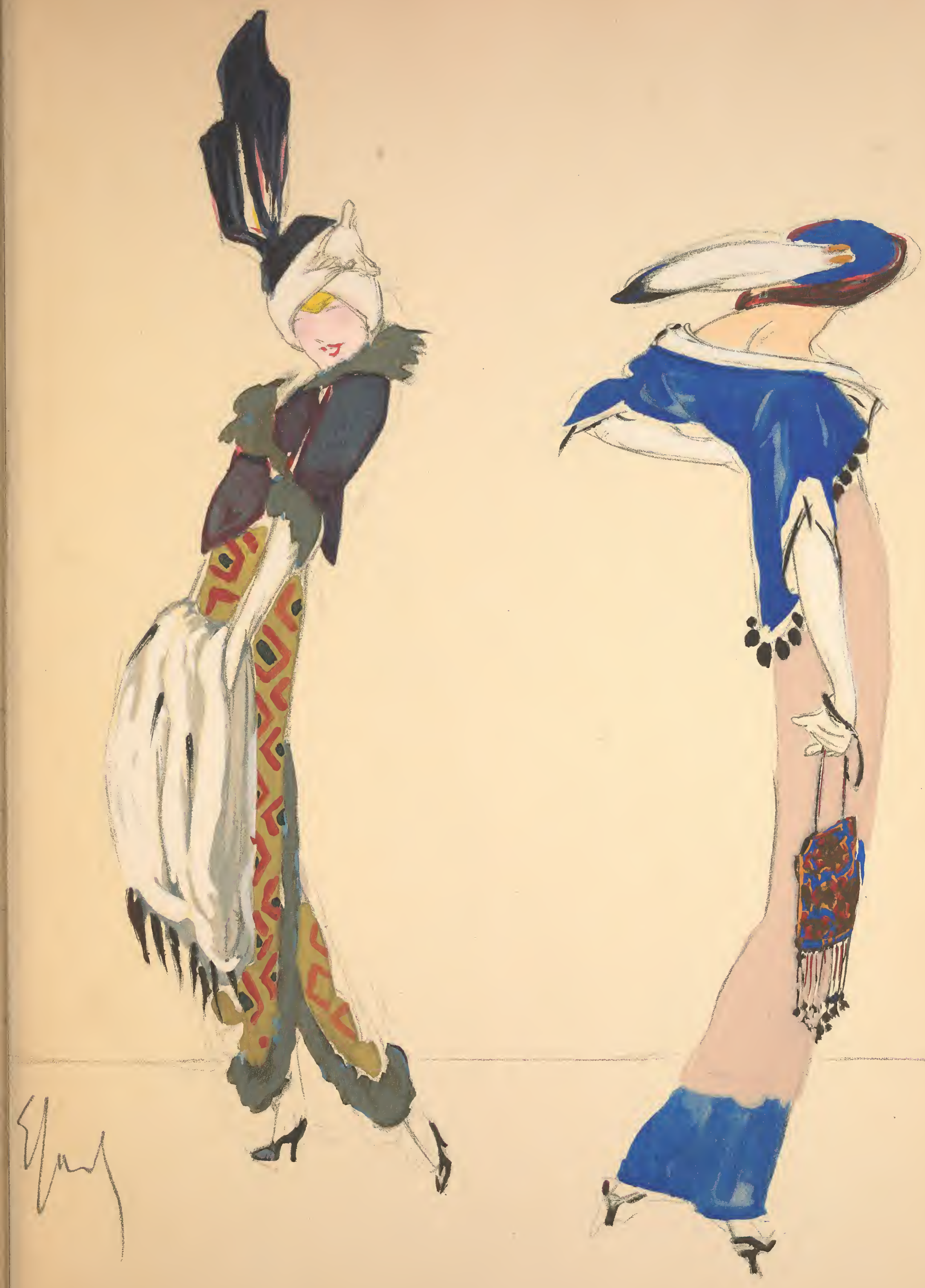




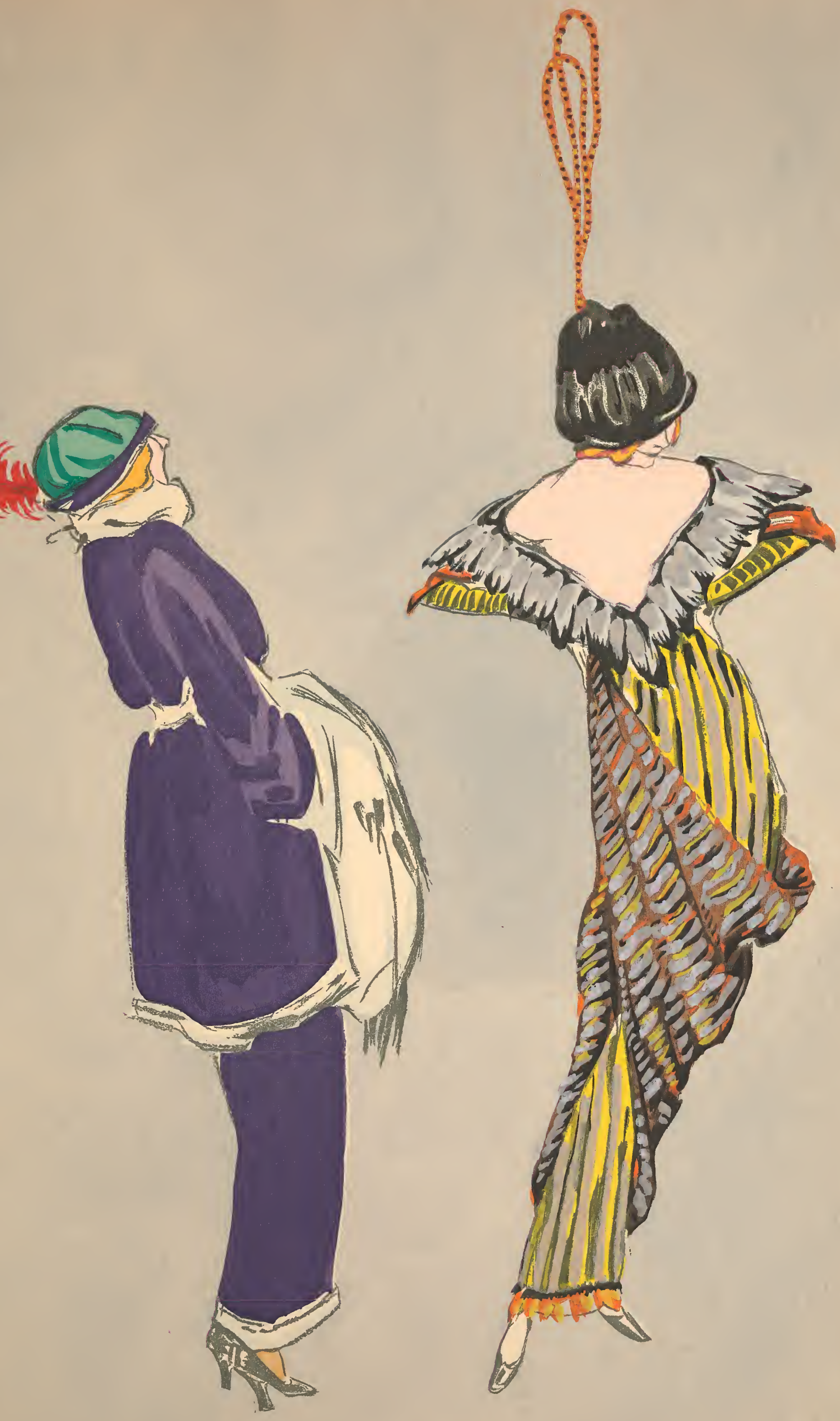


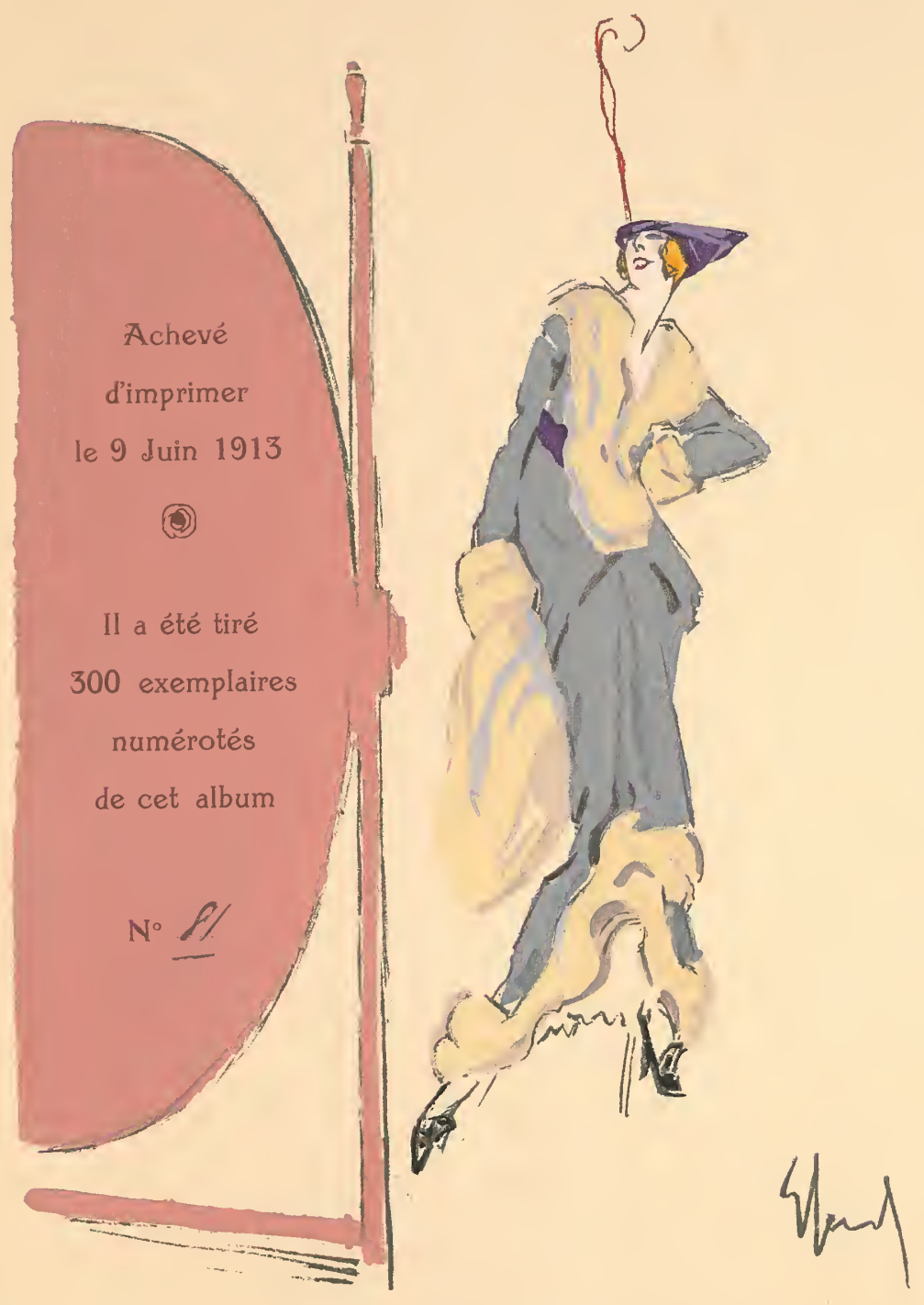






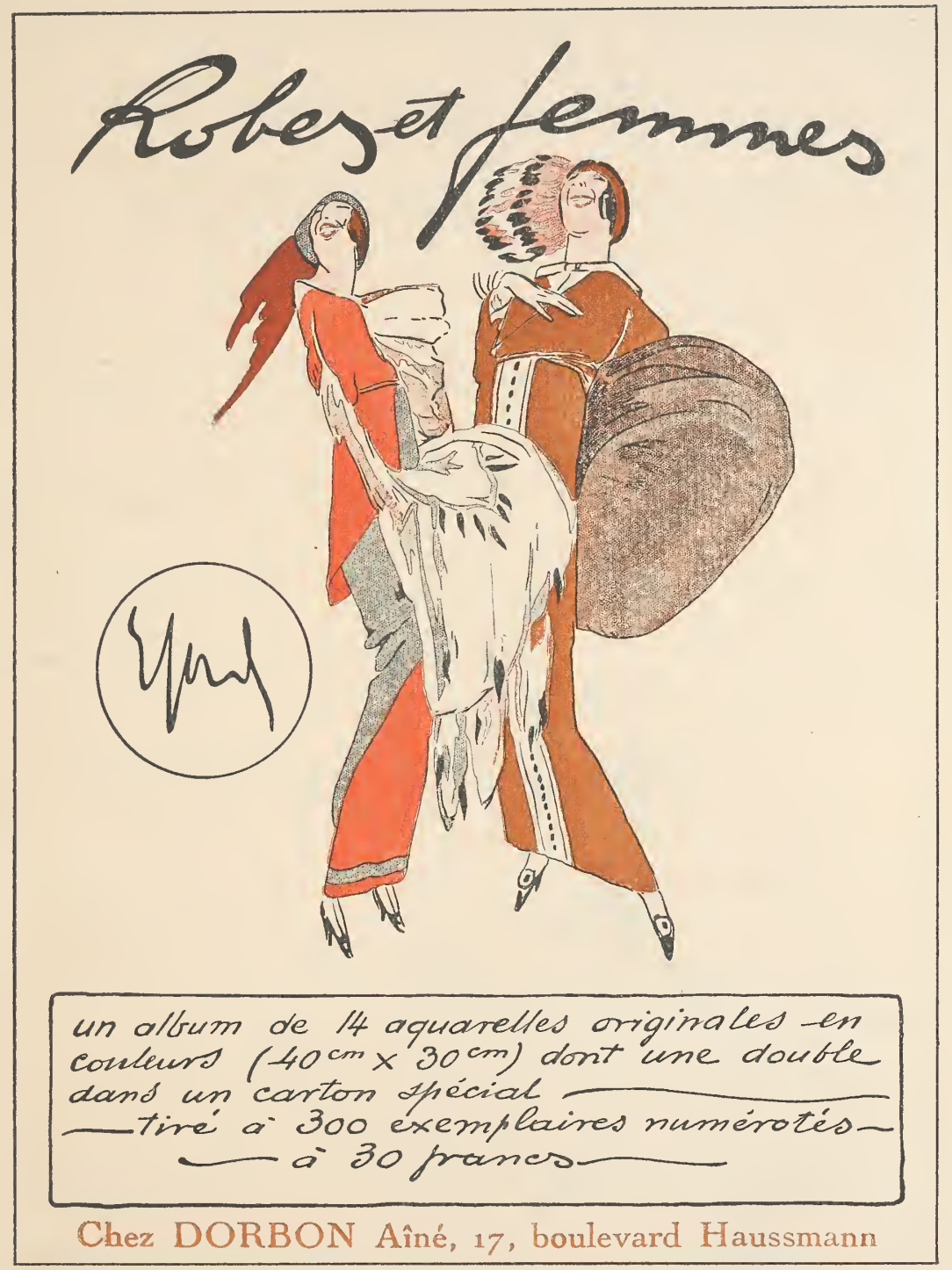

xi 

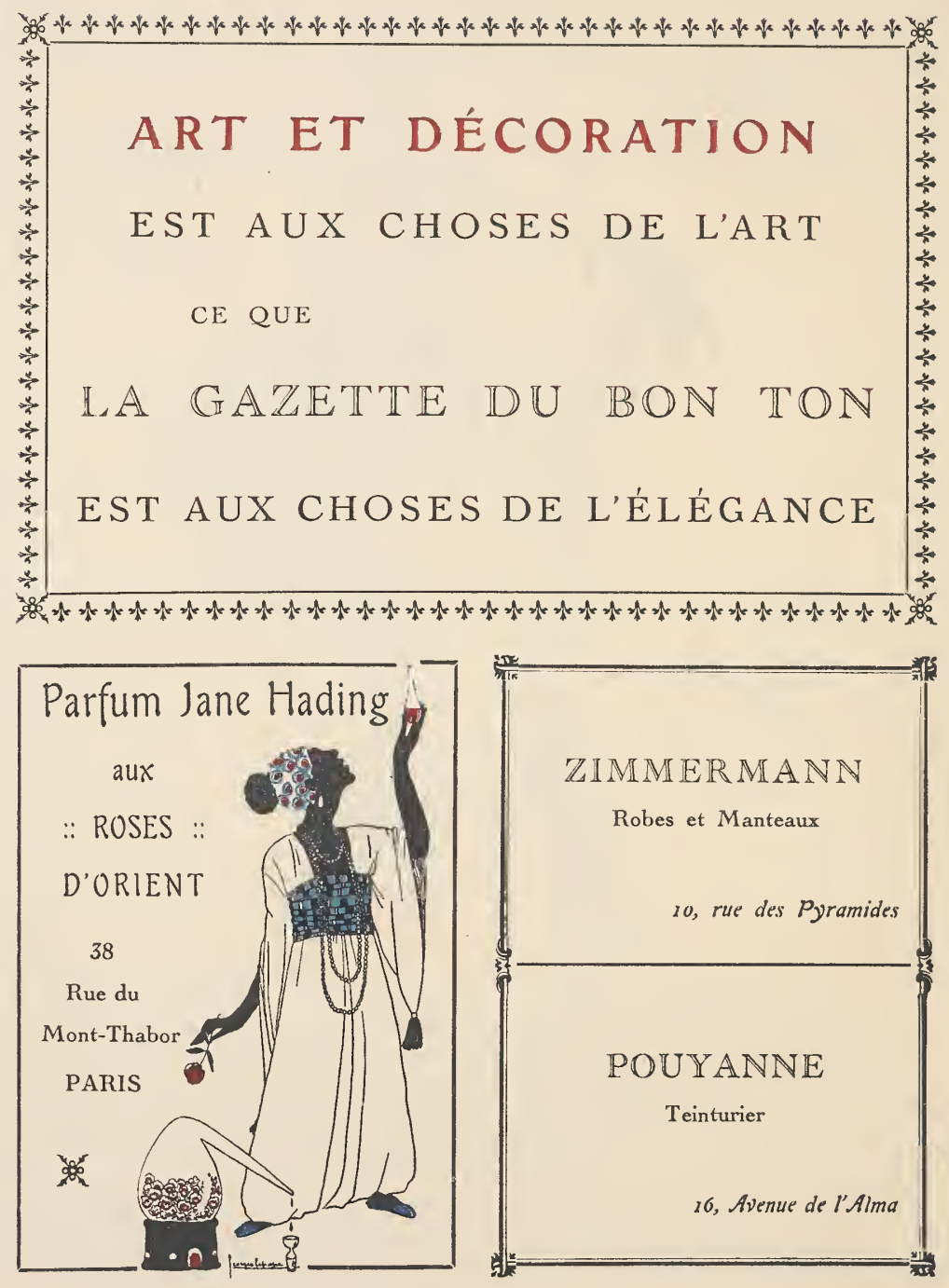




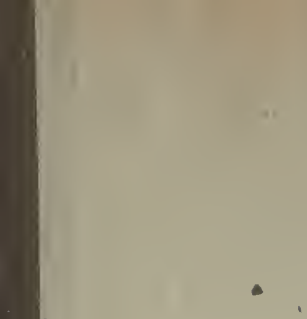


